\title{
Collaborative work as a teaching-learning strategy, a powerful tool for the 21 st century
}

\author{
Liz Karen Herrera Quintero, $\mathrm{PhD}^{1}$, María Alejandra Guzmán Pardo, $\mathrm{PhD}^{1}$, Andres Fernando Gil Plazas, Eng ${ }^{3}$ \\ ${ }^{1}$ Universidad Nacional de Colombia, Facultad de Ingeniería Mecánica y Mecatrónica, Colombia, \\ lkherreraq@unal.edu.co,maguzmanp@unal.edu.co \\ ${ }^{3}$ Servicio Nacional de Aprendizaje SENA, Centro de Materiales y Ensayos, Colombia, \\ aisisae@misena.edu.co
}

\begin{abstract}
Mechanical engineering, a program that has existed for more than 50 years at Universidad Nacional de Colombia, has undergone adjustments in accordance with the dynamics of the institution over time. It is a leader in the country in the training of mechanical engineers, who contribute solutions to meet the needs of society. The program has strengthened its research and training capacity in recent years, supported by funding programs and support to improve the laboratories, research groups and departments offered by the university and the faculty. In engineering education, the program must develop professional skills, including applying engineering knowledge; designing and conducting experiments; identifying, formulating and solving engineering problems; recognizing contemporary problems; and using modern techniques and tools for the practice of engineering.
\end{abstract}

The application of information and communications technology (ICT), problem-based learning (PBL), and concurrent engineering (CE) tools plays a critical role in allowing students to understand the professional roles in the industry. The Industrial 4.0 technology is an example of a system that is integral in helping learners relate better to events taking place in the real world. Similarly, teaching and learning methodologies must integrate platforms that promote professionalism, allowing learners to connect with the future.

In this research, we propose to study and answer the research question: from the students' perspective, to what extent a $P B L$ approach, including concurrent engineering methodologies and ICT tools in a manufacturing processes course, contributes to bridging the gap between technical and professional or interpersonal skills. We focus on the impact of collaborative learning as a useful tool to achieve the development of a project based on learning competencies through the use of ICT tools and work methodologies as concurrent engineering. Finally, We emphasize the digitalization process as a way to help students interact and exchange knowledge, which fosters a sense of community.

\section{INTRODUCTION}

\section{A. Higher education in the digital age}

The digitization of the world has affected various aspect and area of our world. We may imagine the turn that is taking place, whereby the due to the digitization, the academics are being turned from book based to the internet-based academics [1]. The changes that are being experienced, affects the society

Digital Object Identifier (DOI):

http://dx.doi.org/10.18687/LACCEI2019.1.1.305

ISBN: 978-0-9993443-6-1 ISSN: 2414-6390 and how the academics progress is being adhered to. Every aspect as far as academics are concerned is adopting online platforms. Research and knowledge communication in the higher education is on increase using the online platforms. The learning and teaching

in the higher education is currently embracing the online features to promote the knowledge. The traditional media, on which the leaning process or the passages of knowledge process were founded, are being drowned by the digitization. In the higher education, the use of the digital materials has allowed the decentralization of the teaching process. The product-oriented learning process has also been decentralized, that is the learning can be accessed by any person anywhere at any time.

The implementation of the modern form of the learning and teaching process is very much important. The Digitalbased teaching serves a very crucial role in the development of the scientifically grounded approaches to any learning process in this world that is evolving now and then [1].

The main objective of embracing digital platforms in education is to make sure, that at least every student in higher education is able to use media skills in their professional life in this era of the digital age. [2].

University which is a higher learning institution has to provide an opportunity, for analyzing and discuss in broad, the impact of the digital platform in our learning systems, the impact on our society and also the major roles played by the change in media of the learning [3]. The higher learning institution has to be forefront in embracing the digitization process and also give correct and give direction on how to go about with the digitization of the learning process [4]. The university has to be the suitable ground or place for the innovations and represent the critical thinker in our society.

The dominance of the digitization influence is consistent with the unification of the learning and the modernity of the skills utilized in the society. Globally, there is push for the social rights and equality in a higher education sector and push for the free critical thinkers in our society. As the whole world moving into digitization, there is emerges of the fake news. In this digital age, it is very crucial for the learners that embrace

$17^{\text {th }}$ LACCEI International Multi-Conference for Engineering, Education, and Technology: "Industry, Innovation, And Infrastructure for Sustainable Cities and Communities", 24-26 July 2019, Jamaica. 
the digital platforms, to be independently reviewing and evaluating the information on the online media, to establish the accuracy and relevance of the information [4]. There is a lot has to be done on our learners, to develop the necessary skills for the today challenges. Self-reflection learning gives the chance to the students, to be in charge and be responsible for their own studies.

\section{B. Collaborative learning}

Collaborative learning is a composition of various educational approaches, which in most cases involves intellectual efforts of both students and teachers or among the students [5]. In collaborative learning, real opportunities are offered to the students in developing professional or interpersonal skills, developing a self-critical thinking mind and above all achieving valuable values when it comes to the development of project learning competency. During the collaborative sessions, the students engage themselves in the groups that are task oriented. The informed teachers always make decisions, based on the collective, the ideas and the views from the scholars and the practices [3]. By the reflective teaching, cooperation is promoted rather than competition among the students. With cooperative learning the main goal is to make sure that students or even teachers work together while collaborative learning mainly focuses on the reflective individuals, self-determined people and the eloquence.

Collaborative learning takes into account, the setting of objectives and planning activities [1]. Due to this, collaborative learning is a useful tool in when it comes to projects. Since projects involve; setting up the objectives of the project, organized and target practices and planning, all these skills the learners are exposed to them in the collaborative learning. The attitude and willingness to learn is taken into account by the collaborative assessments. Elements like knowledge, attitude, and skills in the collaborative learning are in a close relationship with the learning to learn competencies in the project management. By the learning to learn competencies, the students are able to communicate via new innovations that are by building on the interactive knowledge for construction and providing solutions to the realworld problems [5]. Project work on the collaborative learning always was the best both from the learners or the teachers involved. This was because the experimental teams familiarized with the process.

\section{The technology as a new learning tool}

Germany, Italy, France, and the United States launched initiatives seeking to launch, implement, and adopt Industry 4.0 also named Industria Conectada 4.0. The program was structured into four main categories including promoting multidisciplinary collaboration, adoption of Industry 4.0 technologies, boosting the development of Industry 4.0 enabler organization, and developing knowledge and competency on Industry 4.0 [6]. To execute the program, training on ICT is paramount, which will also facilitate professional development based on computational technologies, teamwork, and simulation technologies.

CAX-PLM (Computer-aided technologies - Product lifecycle management), one of the systems supporting the Industrial 4.0 has played a significant role in managing sources of true data sets such as the product digital models. The system is linked to different professional profiles that demand knowledge and skills on specific application confirming to the wide range of tools [7]. Students, therefore, need to be trained on how they can use these applications in performing tasks in engineering and in the process promote learning. ProjectBased Learning models are important in acquiring and developing knowledge by looking at issues from the concept of employability [6]. Learners are equipped with skills that are integral in securing employment opportunities and increase productivity.

As it stands, students have a certain degree of freedom in terms of the tools used in studying. Farther on, students are not provided with specific training and tools that will see them improve productivity after securing employment opportunities. There is need to develop project-based working methodologies to conduct the multidisciplinary project. ICT and PLM creates an opportunity for creating materials revealing the professional roles in the industry such as project manager, mechanical designer, and tool designers [6]. Learners will improve their skills and ability to perform beyond expectation. It will also create opportunities for learners to equip themselves with skills that will be essential in building their careers in future. Farther on, the teachers will have an easier time sharing knowledge with learners.

\section{PROJECT BASED LEARNING - PBL}

\section{A. PBL on a shoestring}

Regarding the PBL approach, from a conceptual point of view, Savin-Baden [8] said in defining the PBL model II (problem-based learning for professional action) that "this model of problem-based learning has, as its overarching concept, the notion of 'knowhow.' Action is seen here as the defining principle of the curriculum whereby learning is both around what it will enable students to be able to do and around mechanisms that are perceived to enable students to become competent to practice." For PBL implementation in the Manufacturing Processes I course of the Mechanical and Mechatronics Engineering Department, of the models proposed by Savin-Baden [8], model II is closest to our context. 
PBL on a shoestring occurs with minimal cost and interruption to other areas of the program. A few professors in the faculty are keen to implement it, perhaps in the face of resistance by other professors.

Savin-Baden et al [9] also said of curriculum model II in PBL (PBL on a shoestring) that "this (model) tends to be implemented in modules run by staff interested in it and avoided by those who disagree with it. The result is that problem-based learning may be used in many modules throughout the curriculum, but there is little real rationale for its implementation in particular areas." Regarding the curricular context, because acting in the model II scenario tends to be scattered throughout the program, students may not understand the rationale for its use, and staff implementing it may feel frustrated by the lack of departmental or institutional support for their PBL on a shoestring.

The current situation is not desirable because there are still no Engineering Faculty guidelines for reforming the entire curriculum to implement PBL, and the obvious difficulty that the students may be overworked if they have to participate in more than one course project simultaneously must be addressed.

\section{B. PBL development}

The Manufacturing Processes I course of the Mechanical and Mechatronics Engineering Department, Universidad Nacional de Colombia, Bogotá, is intended for students in the sixth semester of the mechanical and mechatronics engineering program. The students are usually 19-22 years old, and manufacturing processes is a core subject within the syllabus. The learning outcomes are focused on developing the skills needed to improve productivity, reduce costs, and ensure products and services that fulfill engineering requirements in a manufacturing context. The specific content concerns the volumetric fabrication processes of metallic, ceramic and composite materials used in high-value sectors, such as the automotive, aerospace, civil building, chemistry and petrochemistry industries (Universidad Nacional de Colombia, 2013) [10].

The project is related to the casting, 3D printing and design/simulation processes supported by product life-cycle management (PLM) engineering software tools. Specifically, the laboratory learning project involves the use of the CATIA software by Dassault Systèmes suite for computer-aided design (CAD), computer-aided manufacturing (CAM), computeraided engineering (CAE) to design and analyze a product that will be manufactured by the foundry process. The Procast software is used to verify the correct flow of molten material, and $3 \mathrm{D}$ printing technology is used to manufacture the tool model needed to cast the final piece. Fig. 1 depicts the aforementioned elements of the project.

The learning outcomes were designed collectively with the working group of the manufacturing process course also taking in account the experience of the other authors such as the Iron Range Engineering (IRE) program [11], which defines three important domains utilized in its model of education: design, professionalism and technical aspects. Students can classify the value of their learning in relation to their future career through utilization of the three domains.
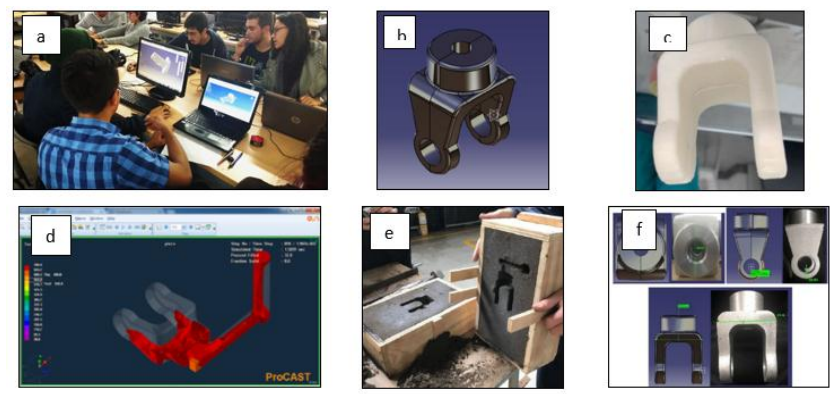

Figure 1. Design and fabrication process.

a) Student teamwork, b) Designed part (CATIA), c) 3D printed part tool, d) Molten flow analysis (Procast), e) Sand mold to cast the part, f) Final casted part

To do this, we debated about establishing the general purpose of the course, such as what a student is expected to know, understand and be able to demonstrate and after completion of a learning path to generate on-going process relating to the goals and outcomes developed to support the training of our mechanical engineer. Another critical point was to identify and select the Identify the main contents and select the desired cognitive levels.

C. Learning competencies development through concurrent engineering of the digitization process in higher learning without a sense of community

During this period (2016-2, 2017-1), the implementation was performed through a use of concurrent engineering and ICT tools in which students worked collaboratively but without a sense of community, meaning that in the developed projects, the knowledge exchange was done only face-to-face and not in a virtual environment.

D. Development of learning competencies through concurrent engineering with a sense of community through the use of ICT tools in the digitalization process in higher learning

During this period (2017-2, 2018-1), the implementation occurs through concurrent engineering and ICT tools and includes a sense of community, with students using the

$17^{\text {th }}$ LACCEI International Multi-Conference for Engineering, Education, and Technology: "Industry, Innovation, And Infrastructure for Sustainable Cities and Communities", 24-26 July 2019, Jamaica. 
3DSwym platform to exchange knowledge in a virtual environment as well as with their peers during class sections.

Dassault Systèmes Learning Lab has developed customization of the 3DEXPERIENCE platform to produce an integrated ePBL framework. The ILICE framework can accommodate any project-based methodology. It is currently being used in diverse open-ended projects in higher and secondary education, in single classrooms and internationally dispersed partnering institutions as well. [12].

To enter the system, students create an account in which the selected work methodology, ILICE (INSPIRE, LEARN, INNOVATE, CREATE, EVALUATE), is established in the dashboard of the Manufacturing Processes course. Under INSPIRE, examples are published in casting process, videos that present animations of how pieces are obtained through this process and photographs of molds that supply a specific need developed by students in previous semesters. These videos show students that there is a real application of the items that are designed and developed in the course. Information is constantly published in LEARN in the form of video tutorials that show students how to use the new tools and commands in the CATIA software.

Next, the students enter INNOVATE, which leads them to participate in a 3DSwym community in which they can join pages and publish content such as images, questions, and responses to surveys. In 3DSwym, students find the first publication, entitled "The Requirements," followed by an image. This publication explains that the published part must be manufactured by casting process or powder metallurgy, and the students must apply the theoretical concepts as well as the practical knowledge obtained in a casting laboratory titled "Implementation of 3D Tools in Processing Parts through Metal Fusion". Through this previously developed laboratory, they know the capacities of the processes as well as the dependent variables, such as time and temperature. The students meet in groups and launch ideas through paper sketches that are then published in the 3DSwym community where other students and facilitators can "like" them and make comments. When the sketches are captured in the community, each publication is transformed into three stages: ideas, concept, and project plan.

These stages are determined by the facilitator. First, the publication of each group is changed to ideas, then to a concept, and finally to a project plan; in the last instance, it becomes a requirement for the team. Then, each working group is transferred to a 3D space, and each student can access four spaces. The first is Content, where students can see the files of each group and also see who created each file. In the Members space, the members of each team and the role of each member are shown. In the Properties space, the leader and owner, or author, creates the fundamental data for the group regarding the name and type of access (public or private). Finally, in the Analytics space, the content of each student is displayed as well as the percentage of participation of each student

The 3D space enables students to generate threedimensional files with the CATIA software so that they can meet the corresponding requirement. The students experience an improvement in comparison to the previously developed activities since they can work collaboratively in terms of how to save the pieces in the 3D space. Each member of the group has immediate access, and the most current version is always available.

The students apply the acquired knowledge and generate results that feed CREATE; although each working group works independently, the groups find different solutions, and they can observe their progress while engaging in healthy competition. When the students have completed the requirement, the facilitator provides feedback through the 3DSwym community, highlighting the strengths and weaknesses, closing the cycle through EVALUATE.

\section{RESEARCH DESIGN}

The experimental research provides an understanding of a situation or phenomenon. This type of research providing a specific treatment to one group and withholding it from another and then determining how both groups scored on an outcome [13]. In the first stage, a quantitative analysis was used to determine whether there was a statistically significant difference between the study populations. In the second stage, a descriptive qualitative method was applied in which an interpretation of the data was carried out based on the observations of the researcher. Thus, a mixed method design was used.

\section{A. Quantitative method}

To determine how is the impact of the students think about the PBL had on their learning their perceptions were investigated at the end of the project through a Google Forms survey to evaluate the functionality of the PBL strategies implemented in the manufacturing processes. The quantitative Google Form survey was sent to the students, and Likert-type items and five-option choices were provided with scores ranging from 1 to 5 (1. Disagree, 2. Usually, 3. Possibly, 4. Agree, and 5. Totally Agree).

The number of participants was 139, and the students were divided into two periods: 71 for the study period 2016-2 and 2017-1, when the methodology used was PBL with concurrent engineering and ICT. In this period, communities such as a strategy of learning were not used; therefore, this

$17^{\text {th }}$ LACCEI International Multi-Conference for Engineering, Education, and Technology: "Industry, Innovation, And Infrastructure for Sustainable Cities and Communities", 24-26 July 2019, Jamaica. 
period is called PBL+CE+ICT WITH NO SENSE OF COMMUNITY and acts as the control group.

For the second period, 2017-2 and 2018-1, the number of participants was 68 , and the methodology used was PBL with the concurrent Engineering and ICT. In addition, communities were used as a strategy of learning. Therefore, this year is called PBL+CE+ICT WITH SENSE OF COMMUNITY.

The survey developed obtained the values of the reliability of the instrument were: for the period 2016-2 Cronbach alpha of 0,71, 2017-1 Cronbach alpha of 0,79, 2017-2 Cronbach alpha of 0,85 and for the period 2018-1 Cronbach alpha of 0,84 . The Cronbach alpha calculated for all periods was 0,84 .

Three categories are declared for the experimental analysis, these categories that were defined are ad hoc due to the experience that has been had with the development of the manufacturing course during the last years as shown in Table 1: category one (technical skills) is composed of six items, category two (professional skills) is composed of three items, and category three (teaching performance) is composed of four items.

TABLE I

DISTRIBUTION OF THE ITEMS BY CATEGORY

\begin{tabular}{|c|c|c|}
\hline CATEGORY & $\begin{array}{c}\text { QUESTIO } \\
\text { N } \\
\text { (ITEMS) }\end{array}$ & DESCRIPTION \\
\hline $\begin{array}{c}\text { CATERGORY 1/ } \\
\text { TECHNICAL } \\
\text { SKILLS }\end{array}$ & $\begin{array}{c}1,2,4,10, \\
11,12\end{array}$ & $\begin{array}{c}\text { Category related to the ability to apply } \\
\text { and acquire knowledge }\end{array}$ \\
\hline $\begin{array}{c}\text { CATERGORY 2/ } \\
\text { PROFESSIONAL } \\
\text { SKILLS }\end{array}$ & $3,6,9$ & $\begin{array}{c}\text { Category related to the methodology } \\
\text { and the educational community }\end{array}$ \\
\hline $\begin{array}{c}\text { CATERGORY 3 } \\
\text { TEACHING } \\
\text { PERFORMANCE }\end{array}$ & $5,7,8,13$ & $\begin{array}{c}\text { Category related to how the teacher } \\
\text { assessed and interacted and related to } \\
\text { workload }\end{array}$ \\
\hline
\end{tabular}

To identify whether there are differences between PBL+CE+ICT WITH NO SENSE OF COMMUNITY and PBL+CE+ICT WITH SENSE OF COMMUNITY, the first hypothesis proposes that there is not statistically significant differences, given that variables of the type ordinal are not convenient for applying parametric methods. Therefore, in this case, we applied a nonparametric method of study called the $U$ Mann-Whitney test using the SPSS V20 software.

TABLE II

RESULTS OF THE NONPARAMETRIC TEST - U MANN-WHITNEY TEST ITEM BY ITEM

\begin{tabular}{|c|c|c|c|c|c|c|c|}
\hline & Q1 & Q2 & Q3 & Q4 & Q5 & Q6 & Q7 \\
\hline $\begin{array}{c}\text { U Mann- } \\
\text { Whitney test }\end{array}$ & 2233.0 & 2390.5 & 1562.5 & 1522.0 & 2386.0 & 2258.5 & 1668.0 \\
\hline Significance & 0.38 & 0.91 & $0.00 *$ & $0.00 *$ & 0.90 & 0.46 & $0.00 *$ \\
\hline
\end{tabular}

\begin{tabular}{|c|c|c|c|c|c|c|}
\hline & Q8 & Q9 & Q10 & Q11 & Q12 & Q13 \\
\hline $\begin{array}{c}\text { U Mann- } \\
\text { Whitney test }\end{array}$ & 1956.5 & 2244.0 & 2156.0 & 2114.5 & 1967.0 & 2347.0 \\
\hline Significance & $0.03 *$ & 0.43 & 0.22 & 0.11 & $0.04 *$ & 0,73 \\
\hline \multicolumn{7}{|c|}{ * Significance $<0.05$} \\
\hline
\end{tabular}

The values reported in Table II indicate that items 3, 4, 7, 8 and 12 have a significance of less than 0.05 , thus showing that the initial hypothesis is null; that is, there is a variance between PBL+CE+ICT WITH NO SENSE OF COMMUNITY and PBL+CE+ICT WITH SENSE OF COMMUNITY. Therefore, to identify the questions that had higher or lower scores, we group the values obtained by categories, numerically and graphically, to emphasize their values regarding the rank obtained.

\section{b. Mixed method}

For the first category in which the six items are grouped, as shown in Fig. 2, that two items were affected. In general terms, this effect can be concluded to be negative, implying that it is not appropriate to implement work communities to enhance technical skills. However, since the nature of the data, especially items 4 and 12, is highly dispersed, so that conclusion could be too hasty.

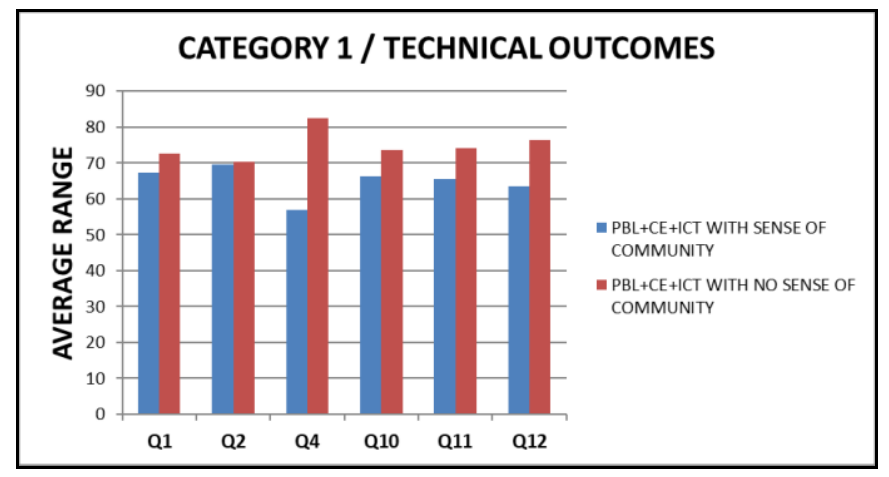

Figure 2. Distribution of range - technical outcomes

In the category of professional skills, composed of three items, there is a significance of less than 0.05, as shown in Fig. 3. Specifically, for question three, category two was affected. Therefore, we can conclude that during the period PBL+CE+ICT WITH NO SENSE OF COMMUNITY vs. PBL+CE+ICT WITH SENSE OF COMMUNITY, the answers to the question Do you think that the way to do the project during the semester involves the development of autonomous learning? showed a decrease in satisfaction, which shows that making use of learning communities promotes better management of professional or interpersonal skills. However, there is a negative impact on technical skills in that constant interaction is generated among the students who make up the study group, which leads to a higher time commitment

$17^{\text {th }}$ LACCEI International Multi-Conference for Engineering, Education, and Technology: "Industry, Innovation, And Infrastructure for Sustainable Cities and Communities", 24-26 July 2019, Jamaica. 
to interact in order to establish better communication; this situation directly affects the decrease in autonomous skills, meaning the effect may result in a loss of responsibility.

Self-Direct Learning (SDL) is one of the goals of PBL. SDL refers to a student's ability to take control of his/her own learning needs, set objectives, and achieve those objectives. The main aim of SDL is to develop a free, mature student. Therefore, SDL is a process through which a student achieves autonomy, maturity, and authenticity in learning. PBL, in contrast, refers to the process of learning in which a group of students comes together to evaluate and understand specific problems with the aim of developing adequate solutions through collaboration. Given that students' prior knowledge of the problems to be solved is limited, PBL requires students to employ SDL to understand their learning needs and develop means to meet those needs. Therefore, SDL is both a goal and a strategy in PBL.

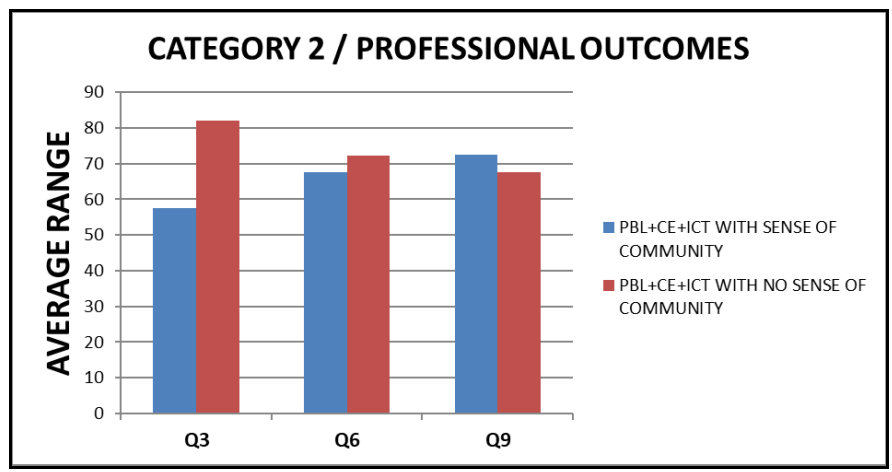

Figure 3. Distribution of range - professional outcomes

The third category seeks to evaluate teaching performance and to determine whether the development of the PBL methodology over the four periods was constant. As shown in Fig. 5, as the time progressed, it became challenging to develop a constant progression because the consumption of materials for training increased. In this case, the items where there was greater dispersion, such as Q7 and Q8, were analyzed separately; that is, implementing work communities did not necessarily advantage or disadvantage learning through PBL.

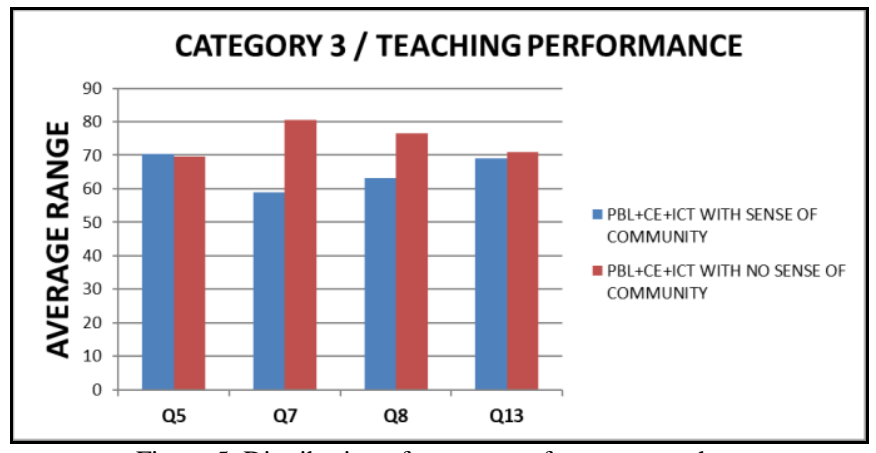

Figure 5. Distribution of range - performance teachers
This finding shows that implementing $\mathrm{PBL}$ in manufacturing engineering needs a more significant economic investment; however, this conclusion must take into account the fact that the observations expressed by students in answering item Q7 are contained in a survey completed through Google Forms. In this category, the impact is significant given that two of four questions were affected. However, as previously mentioned, the responses may be inconclusive in terms of assessing whether the learning community is responsible for such a change.

Then, using the same method as in the previous evaluation, the U Mann-Whitney test was used to evaluate whether the effect of all the questions given the categories represented a specific change. In the same way, it is proposed as an initial hypothesis that there is no statistically significant differences between the all periods PBL+CE+ICT WITH NO SENSE OF COMMUNITY vs PBL+CE+ICT WITH SENSE OF COMMUNITY

However, in general terms, based on the results of the survey, the values show that the implementation of learning communities does not help promote better development of technical skills, there is no effect on professional skills when the questions are grouped, and an item-by-item analysis shows that the SDL could be affected. Teaching performance has a significance less than 0.05 in this order of ideas; the community has an effect on these categories, but the previously mentioned observation explains that the effect is great due to Q7, not strictly owing to community.

To justify why the learning community affects technical competences and also to contrapose the responses because professional skills did not show an effect when the items were grouped, an analysis of the grades obtained during the four academic periods conducted between the groups PBL+CE+ICT WITH NO SENSE OF COMMUNITY and PBL+CE+ICT WITH SENSE OF COMMUNITY, with the students as the object of study.

The analysis made of the students' grades is shown following: from each semester two grades values were obtained, the grade associated with the autonomous work, which referred to evaluations of technical knowledge about topics seen in class (self-learning). The grade associated with group work, which consisted of evaluation of the professional skills where students could share, discuss and execute in different projects. These two grades values were calculated, and a final grade value was obtained.

The results of the Table 3 indicates that there are significant differences between the control group (PBL $+\mathrm{CE}+$ ICT WITH NO SENSE OF COMMUNITY) and experimental

$17^{\text {th }}$ LACCEI International Multi-Conference for Engineering, Education, and Technology: "Industry, Innovation, And Infrastructure for Sustainable Cities and Communities”, 24-26 July 2019, Jamaica. 
$(\mathrm{PBL}+\mathrm{CE}+\mathrm{ICT}$ WITH SENSE OF COMMUNITY) in relation to autonomous work. That is, the control group (2016II and 2017-I) had a better performance in this type of theoretical evaluation than the experimental group. Nevertheless, significant differences were also obtained between the groups in relation to teamwork. The experimental group (2017-II and 2018-I) had a better performance in the practical evaluation than the control group. No significant differences were observed in relation to the final grade, however, it is worth mentioning that the final grade of the course does not constitute or demonstrate that there is an effect of the learning community or the use of the CE and ICT, as if it could be identified in the autonomous work and the group work of the periods studied.

TABLE III

RESULTS OF U MANN-WHITNEY TEST FOR OBTAINED GRADES

\begin{tabular}{|c|c|c|c|}
\hline & $\begin{array}{c}\text { AUTONOMOUS } \\
\text { WORK }\end{array}$ & $\begin{array}{c}\text { GROUP } \\
\text { WORK }\end{array}$ & $\begin{array}{c}\text { FINAL } \\
\text { GRADES }\end{array}$ \\
\hline $\begin{array}{c}\text { U de Mann- } \\
\text { Whitney }\end{array}$ & 2312.50 & 1849,00 & 2520,00 \\
\hline Significance & $0,02 *$ & $0,00 *$ & 0,13 \\
\hline \multicolumn{4}{|c|}{ *Significance $<0.05$} \\
\hline
\end{tabular}

Given that the Significance is less than 0.05 in the autonomous work, we can conclude that the learning community affects the obtaining of technical skills that are a function of autonomous work, as mentioned above, because the community demands a greater time commitment that prevents the student from concentrating on the development of SDL. Thus, being immersed in a learning community in a virtual environment can negatively affect the student's concentration.

SDL as a strategy for PBL is viewed in terms of the degree of control that the student has over his or her learning process. In PBL, SDL is defined as a student's preparedness to participate in self-defined learning activities [14]. According to Loyens et al. [14], the definition of SDL in PBL emphasizes the student's autonomy and willingness to engage in learning. This definition indicates the major aspects of SDL: "personal autonomy, self-management in learning, the independent pursuit of learning, and learner control of instructions" [14]. Although PBL involves a tutor or a professor, the student members of the group retain autonomy in finding the solutions to the problems they are meant to solve. Given that PBL is employed prior to gaining knowledge of the problem, the students are forced into SDL. At that stage of PBL, the students must identify their learning needs, set objectives, identify resources, and determine strategies for the achievement of the objectives. Measuring students' ability to identify solutions to the problem can serve as a means of evaluating SDL.

\section{CONCLUSIONS}

Based on the teacher's observations and the use of quantitative tools, it was found that the learning communities improved the students perception of technical skills, and it was also found that the knowledge acquired during the training helped students obtain an understanding of manufacturing processes.

Concerning professional skills, the U Mann-Whitney test revealed a conflict between the students perceptions and the teachers perceptions. In this way has given rise to disagreement, it nonetheless appears appropriate to clarify this approach. The quantitative analysis of the students grades was done and revealed that the sense of community improves professional skills when the student uses ICT tools and concurrent engineering

In this research the learning community contributes to the development of professional skills in terms of group work; if technical skills were evaluated only on a group basis, the community would be a good tool to enhance technical skills, meaning that the professional skill enhances the technical skill from the group perspective and diminishes autonomous work on the part of the student.

We emphasize that the sense of community is a useful tool for the development of professional skills, as shown by the applied experimental research, which is composed of quantitative analysis through nonparametric statistical analysis using the U Mann-Whitney method.

The collaborative work developed during the two study periods showed that students were satisfied with their perception of the development of learning competencies through the use of information and communication tools, as well as concurrent engineering. This data is useful given that the student is the center of learning, and if we see the student as a client, where the university provides services, it must be focused on maintaining its clients (students) with a high level of satisfaction, which contributes to continuous improvement

\section{ACKNOWLEDGMENT}

We would like to thank to the professor Erik de Graff and the staff of the master's degree in problem-based learning in engineering and science at the University of Aalborg, who created an exciting learning environment that generated transformative learning in the perception of being a professor. The results of this work are an integral part of the thesis of the MPBL program at the University of Aalborg.

This research was supported by the Autonomous Patrimony National Financing Fund for Science, Technology, and Innovation, Francisco José de Caldas, Colciencias (Contract PULFAB Code FP44842-091-2016). We are also grateful to the SENA, Materials and Testing Center of the 
Regional Capital District for providing support of the learning process.

\section{REFERENCES}

[1] Kergel D., Heidkamp B., Telléus P., Rachwal T., Nowakowski S. (2018) "Introduction to the Book: The Digital Turn in Higher Education MultiDisciplinary and International Perspectives" in Kergel D., Heidkamp B., Telléus P., Rachwal T., Nowakowski S. (eds). The Digital Turn in Higher Education: International Perspectives on Learning and Teaching in a Changing World. Springer, 7-14.

[2] Ryberg T., Davidsen J. (2018) "Establishing a Sense of Community, Interaction, and Knowledge Exchange Among Students." In: Kergel D., Heidkamp B., Telléus P., Rachwal T., Nowakowski S. (eds) The Digital Turn in Higher Education. Springer VS, Wiesbaden 143-160.

[3] Blaschke, L.M (2018) "Self-determined Learning (Heutagogy) and Digital Media Creating integrated Educational Environments for Developing Lifelong Learning Skills." In: Kergel D., Heidkamp B., Telléus P., Rachwal T., Nowakowski S. (eds) The Digital Turn in Higher Education. Springer VS, Wiesbaden 2018. 129-140.

[4] Sørensen M.T (2018) "The Students' Choice of Technology A pragmatic and outcome-focused Approach" In: Kergel D., Heidkamp B., Telléus P., Rachwal T., Nowakowski S. (eds) The Digital Turn in Higher Education: International Perspectives on Learning and Teaching in a Changing World. Springer VS, Wiesbaden 161-174.

[5] Gaunt, H., Westerlund H, eds. Collaborative learning in higher music education. Routledge, 2016.

[6] Ríos, J., Mas, F., Marcos Bárcena, M., Vila, C., Ugarte, D., \&amp; Chevrot, T. (2017). Accelerating the Adoption of Industry 4.0 Supporting Technologies in Manufacturing Engineering Courses. In Materials Science Forum. Trans Tech Publications. 903, 100-111.

[7] Mourtzis, D., Vlachou, E., Dimitrakopoulos, G., \&amp; Zogopoulos, V. (2018). Cyber-Physical Systems and Education 4.0 - The Teaching Factory 4.0 Concept. Procedia Manufacturing, 23, 129-134.

[8] Savin-Baden, M. (2000). Problem-based Learning in higher education: Untold stories. Buckingham, Open University Press/SRHE.

[9] Savin-Baden, M., Major, C. (2004). Foundations of problem-based learning. Maidenhead, Open University Press/SRHE.

[10] Universidad Nacional de Colombia. (2013). Pregrado Ingeniería Mecánica. Retrieved from 22-01-2017 from Universidad Nacional de Colombia Web Site https://www.ingenieria.bogota.unal.edu.co/formacion/pregrado/ingenieria -mecanica

[11] Johnson, B., Ulseth, R. (2017) “The iron Range engineering model" In Guerra, A., Ulseth, R., Kolmos A. (eds). PBL in Engineering Education: International Perspectives on Curriculum Change. Rotterdam, Sense Publishers. 53-69

[12] Fouger, X. (2018) 'The Deployment Problem of Problem Based Learning Academic Transformation too can be Digitally Enabled'. Available at: https://academy.3ds.com/sites/default/files/2016-09/DS The Deployment Problem of Problem Based Learning.pdf (Accessed: 27, January 2019).

[13] Creswell, J.W. (2013). Research design: Qualitative, quantitative, and mixed methods approaches. Sage publications.

[14] Loyens, S. M., Magda, J.; Rikers, R. M. (2008). Self-directed learning in problem - base learning and its relationships with self-regulated learning. Educational Psychology Review, 20, 411-427.

$17^{\text {th }}$ LACCEI International Multi-Conference for Engineering, Education, and Technology: "Industry, Innovation, And Infrastructure for Sustainable Cities and Communities", 24-26 July 2019, Jamaica. 